\title{
PLANO DE DESLIGAMENTO VOLUNTÁRIO COMO INSTRUMENTO DE GESTÃO DO CAPITAL HUMANO EM UMA EMPRESA PÚBLICA
}

\author{
VOLUNTARY DISPLACEMENT PLAN AS AN INSTRUMENT FOR \\ HUMAN CAPITAL MANAGEMENT IN A PUBLIC COMPANY \\ Rafael Kuramoto Gonzalez \\ Juliana Fagundes
}

Resumo: O objetivo deste estudo é investigar o Plano de Desligamento Voluntário - PDV levantando questões acerca da sua contribuição para gestão do Capital Humano para uma Empresa Pública Federal. O PDV tornou-se um ferramental para a solução de alguns problemas gerenciais na Administração Pública brasileira como corte de despesas, redução do desequilibrio das contas públicas e manutenção de um clima organizacional saudável. Para a operacionalização desta pesquisa, realizou-se pesquisa documental valendo-se de documentos como Nota Técnica do programa e relatório de resultados, além de entrevistas com atores chave. A apresentação dos resultados destacou a carreira mais sensível com relação aos desligamentos e as entrevistas o valor da transmissão de conhecimento proporcionada pelo PDV. Conclui-se que o PDV pode ser o momento para gestão do Capital Humano, permitindo à empresa se preparar para a perda de profissionais e ao transmitir conhecimentos para outros.

palavras chave: Plano de Desligamento Voluntário; Capital Humano; Empresa Pública.

AbSTRACT: It is concluded that the POS can be the moment for Human Capital management, allowing the company to prepare for the loss of professionals and to transmit knowledge to others.

The purpose of this study is to investigate the Voluntary Displacement Plan - VDP raising questions about its contribution for Human Capital management in a Federal public company. The VDP became a useful tool for solving some management problems in the Brazilian Public Administration such as cutting/reducing expenses, mitigate the imbalance of public accounts and maintaining a healthy organizational climate. For the operationalization of this research, was done documentary research using documents such as Programme Technical Notes and result reports, in addition to interviews with key actors. The presentation of the results highlighted the most sensitive career with regard to dismiss and the interviews showed the value of knowledge transmission provided by VDP. It is concluded that the VDP can be the moment for Human Capital management, allowing the company to be prepared for professional's loss and to transmit knowledge to othrs.

palavras chave: Voluntary Displacement Plan; Human Capital; Public Company. 


\section{INTRODUÇÃO}

O ambiente competitivo do mundo empresarial vem fazendo com que as organizações sintam a necessidade de provocar e acompanhar as mudanças, o que consequentemente reflete em suas formas de gestão.

Em nome do aumento da competitividade, as organizações utilizam as mais diversas ferramentas gerencias. Os Planos de Desligamento Voluntário são oriundos dessas mudanças, pelas quais as organizações passam, a fim de torná-las mais competitivas (Ghiorzi, 2004).

Ao longo dos últimos anos, na Administração Pública brasileira, o desligamento voluntário se estabeleceu como solução para o corte de despesas com pessoal e redução do desequilíbrio das contas públicas (Guedes, et. al., 1998), sendo encarados como ferramentas para redução do quadro de funcionários, e, paralelamente, para reduzir os custos com causas trabalhistas, buscando manter o clima organizacional saudável (Barbosa, et. al., 2011).

O Plano de Desligamento Voluntário pode, no entanto, ser encarado como instrumento que possibilite adequação ao modelo de gestão que permita flexibilidade na administração do quadro de pessoal, considerando um quadro de pessoal compatível com o volume de recursos disponíveis e competências necessárias.

Não é incomum na Administração Pública, existirem empregados que exercem e dominam uma atividade por décadas. Como na maioria das vezes os salários desses indivíduos são elevados quando comparados ao que receberiam se optassem pela aposentadoria e ainda por a demissão não ser prática recorrente nas Empresas Públicas e não existir a obrigatoriedade de aposentadoria, muitos empregados acabam por adoecer, devido à idade avançada, ou por falecer ainda no exercício da função.

Diante dessa situação, pode-se afirmar que a Administração Pública perde com relação à produtividade e perde conhecimento especializado sem a necessária preparação para a substituição por não vislumbrar a perda do empregado.

Neste caso, o presente estudo propõe-se a investigar o Plano de Desligamento Voluntário levantando e analisando questões acerca da sua contribuição para gestão do Capital Humano no âmbito de uma Empresa Pública Federal, justificando-se o estudo como contribuição acadêmica e empresarial dentro deste escopo.

Face à problemática relatada acima, busca-se responder à seguinte questão de pesquisa: a adoção de um Plano de Desligamento Voluntário em uma Empresa Pública pode ser instrumento para a Gestão do Capital Humano?

O estudo espera concluir que um Plano de Desligamento Voluntário é uma estratégia positiva para oxigenação e manutenção do nível de conhecimento no que se refere à mão de obra, considerando a Gestão do Capital Humano. 
Esse estudo tem como objeto Empresa Pública Federal de abrangência nacional que atua no setor gráfico que está estabelecida há mais de três (3) séculos.

O estudo se dará a partir da análise de conteúdo de documentos tais como Regulamento do Plano de Desligamento Voluntário, Nota Técnica fundamentadora, relatórios de análise, dentre outros documentos, além da análise de discurso das entrevistas.

O trabalho está estruturado de forma que no Capítulo 2 está apresentada a Fundamentação Teórica sobre os principais tópicos estudados, o que dizem os principais estudiosos sobre Planos de Desligamento Voluntário, mudanças ambientais e Capital Humano. O capítulo 3 tratará da metodologia, considerando o tipo de pesquisa quanto à natureza, abordagem, procedimentos e técnicas de coleta de dados utilizadas. Por fim, serão discutidos os dados no capítulo 5, realizada a conclusão no capítulo 6 e as referências bibliográficas expostas no capítulo 7 .

\section{FUNDAMENTAÇÃO TEÓRICA}

O objetivo desta seção é apresentar os principais conceitos que serão abordados na pesquisa. A seção realiza um resgate das definições conceituais dos principais constructos utilizados na pesquisa, como mudanças ambientais, Planos de Desligamento Voluntário e Capital Humano.

\subsection{MUDANÇAS AMBIENTAIS}

Thornhill e Gibbons (1997 apud Ghiorzi, 2004, p.37) afirmam que ainda que não tenha sido o objetivo, as privatizações, o avanço tecnológico e as reengenharias vêm obrigando as empresas a reduzirem seu quadro de pessoal para garantir competitividade.

Dentre as mudanças necessárias devem-se citar as estruturas e organizações flexíveis de trabalho, resiliência e processos decisórios rápidos o que demanda pessoas atualizadas com o mercado e campo de atuação (Dutra, 2002). Em Caldas (2000), reflete-se que inevitavelmente as demissões são o meio mais adequado de promover mudanças organizacionais.

É preciso considerar que as pressões externas e internas que sofrem as empresas não afetam apenas suas estruturas, mercados e produtos, mas principalmente seus padrões culturais e políticos. Essas mudanças não são episódicas, e sim processos contínuos na vida das empresas que querem se manter vivas (Silva et. al., 2009).

\subsection{PLANOS DE DESLIGAMENTO VOLUNTÁRIO}

Os Planos de Desligamento Voluntário podem ser definidos como "programas que oferecem aos trabalhadores alguns incentivos para que solicitem seu desligamento da empresa" (Bessi e Grisci, 2003, p.1) ou como uma forma de desligamento concebido para interessar a 
um número expressivo e específico de pessoas, que em troca de um conjunto de incentivos financeiros e não financeiros, se demitem das organizações (Leme e Mazzili, 2001).

De acordo com a segunda definição, através do Plano de Desligamento Voluntário procura-se suprir as necessidades da organização, de diminuição de seu quadro por meio de incentivos ao desligamento (Leme e Mazzili, 2001).

Long e Thean, (2011 apud Monteiro, 2012) definem a demissão voluntária como um processo em que o empregado toma decisão conscientemente se quer permanecer ligado ou deixar a organização.

Assim, o PDV apesar de ser um instrumento administrativo de redução do quadro de pessoal, realiza-o de forma menos traumática diante dos benefícios socias e pecuniários oferecidos aos empregados, como forma de incentivar aqueles que se propõem a se desligar (Silva et. al., 2009).

O presente trabalho entende que as definições expostas possuem em si a mesma essência, mas adotará as definições apresentadas por Leme e Mazilli (2001) e Long e Thean, (2011 apud Monteiro, 2012) por entender que são complementares, pois uma apresenta a perspectiva da organização e a outra do empregado.

Segundo Caldas (1999 apud Silva et. al., 2009), os processos de demissão coletiva para enxugamento do quadro de pessoal, através de Planos de Demissão Voluntária, vêm sendo adotados no Brasil tanto no setor público quanto no privado desde as Privatizações que marcaram o Governo de Fernando Henrique Cardoso na década de 1990.

Barbosa et. al. (2011) ressaltam que as razões que levam as empresas a implantarem os PDV's são as mais distintas e entre elas destacam-se: necessidade de aumentar lucros, readequação do quadro de empregados, automação e modernização e a renovação do quadro pelo incentivo à aposentadoria. Acrescenta-se ainda desburocratização e diminuição de encargos com a folha de empregados (Leme, 2000).

Caldas (2000) traz que os processos de enxugamento, ou Planos de Desligamento não são mais instrumentos a serem utilizados em uma conjuntura específica, são um sistema permanente, práticas estruturais, com previsão de continuidade.

Na mesma esteira, Ghiorzi (2004) afirma que a mudança proporcionada por Planos de Desligamento Voluntários (PDV) é caracterizada como planejada, pois se define por decisões deliberadas em conjunto com o poder organizacional e estruturada, já que implantam medidas de maior impacto em sua estrutura operacional, processual e de negócios.

Ghiorzi (2004) ainda chama atenção para o setor público brasileiro que veio se mantendo estável nos últimos tempos, considerando a turbulência do mercado e se utilizando dos PDV's com intuito de reduzir empregados.

Ainda que o PDV considere todos os custos diretos objetivados e tendo em vista as consequências, deve dedicar especial atenção à perda 
de conhecimento, de capital intelectual, de inteligência, de entendimento e de domínio de processos, como alerta Assis (2010).

Os estudos de Barbosa et. al.(2011) apontam que a evasão de vários funcionários de uma única vez e a perda de funcionários qualificados e especializados é considerada pontos negativos de Plano de Desligamento Voluntário.

Conforme Nomura e Gaidzinski (2005), o ideal é que com a rotatividade gerada a empresa consiga manter os empregados bem qualificados e substituir aqueles que apresentam deficiência no desempenho. Esse cenário corrobora com Spector (2010), pois segundo esse autor, para que uma organização alcance seus objetivos é necessário ter em seu quadro de pessoal empregado que desempenham suas atividades com alto nível de eficiência.

Sendo assim, o planejamento dos Planos de demissão deve levar em conta a perspectiva da organização, pois do contrário há a evasão do conhecimento especializado sem a necessária preparação (Ghiorzi, 2004) deixando sequelas irreparáveis e também a perspectiva do empregado, pois a forma que a empresa trata as demissões reflete a sua valorização ou não do Capital Humano pela empresa (Caldas, 200o).

\subsection{CAPITAL HUMANO}

Conforme relatado na seção que trata do PDV, é importante em qualquer programa de demissão a precupação com o Capital Humano, sua influência sobre o desempenho da organização e o impacto das perdas no que se refere a esse item.

Oliveira e Medeiros (2011) trazem a definiçao de Capital Humano do Centro de Referência Empresarial como a "capacidade, habilidade e experiência quanto ao conhecimento formal que as pessoas detêm e que agregam valor a uma organização".

É importante considerar, conforme afirma Monteiro (2012), que ao deixar a empresa, o empregado leva com ele informações, conhecimentos técnicos e processuais, percepções e modos particulares para alcançar objetivos mais rapidamente. Dessa forma, com o desligamento de um empregado não é só o quantitativo que diminui, mas também uma parte da organização e sua evolução que vai embora.

Silva et. al. (2009) conclui em seu estudo que as possibilidades de aposentadoria antes do esperado, sem que haja planejamento traz preocupações com relação à possibilidade de transferência de conhecimento para novos funcionários.

A Gestão do Capital Humano deve estar ativa na execução de programas de demissão para que a organização não perca conhecimento sem que esteja preparada e consequentemente as demissões não afetem seu desempenho. 


\section{METODOLOGIA}

Esta seção apresenta os principais elementos do design e da estratégia de pesquisa empregadas no estudo. Trata-se de um trabalho de caráter qualitativo, aplicado a uma organização da esfera pública brasileira, com o emprego de materiais documentais e entrevistas para compreender a relação entre Planos de desligamento voluntário, ambiente e gestão do capital humano.

A organização que servirá de instrumento para realização do estudo é uma Empresa Pública de abrangência nacional que atua no mercado gráfico cujo negócio envolve, principalmente, tecnologia, arte e sigilo. Atualmente é composta por cerca de 3.000 empregados e possui uma estrutura hierárquica bem definida, se subdividindo entre dois grupos: administrativo e operacional.

A investigação aqui proposta, acerca da contribuição do Plano de Desligamento Voluntário para a Gestão na Empresa Pública como ferramenta para gestão do Capital Humano terá como foco o Plano de Desligamento Voluntário dessa Empresa buscando analisar desde as diretrizes gerais de tal programa até suas consequências. A figura a seguir representa visualmente a relação que se pretende estudar:

FIGURA 1 - Relação entre os constructos

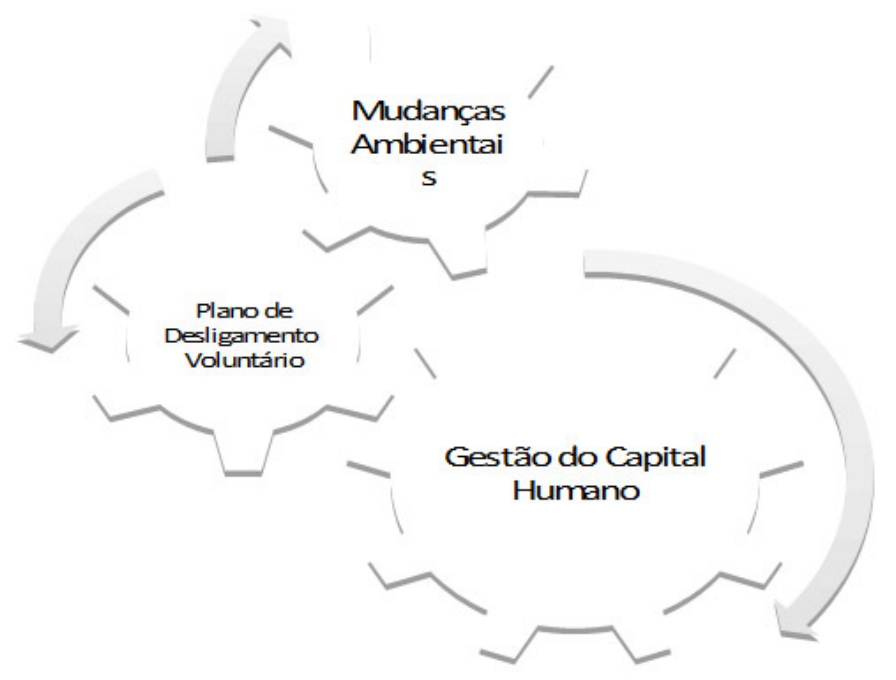

A escolha do objeto em questão se deu pelo interesse profisional da pesquisadora já que esteve envolvida no processo de elaboração e aplicação do programa na empresa que será objeto do estudo. Além de fazer parte do cotidiano da pesquisadora, o assunto pode ser bem explorado tendo em vista a maior facilidade de acesso a dados, tornando viável a pesquisa em termos de sua realização.

Quanto à natureza, será utilizada a pesquisa aplicada, uma vez que, como o próprio nome sugere, e coaduna com objetivo dessa pesquisa, identifica soluções aplicáveis à realidade local.

Para subsidiar a investigação proposta, será realizada pesquisa de abordagem qualitativa. A escolha por este tipo de pesquisa se deu conforme Gerhardt e Silveira (2009), levando em consideração a espe- 
cificidade da ciência social e de suas relações, que os dados analisados serão não métricos e porque as informações aqui se pretendem aprofundadas e ilustrativas.

Para alcance do objetivo, realizar-se-á uma pesquisa descritiva que:

“(...) embora transmitam inicialmente a ideia de que apenas relatam ou descrevem uma situação, elas têm como objetivo principal estabelecer relações entre as variáveis analisadas e levantar hipóteses ou possibilidades para explicar essas relações (não de forma mais definitiva, o que as transformaria em explicativas)." (Bertucci, 2008, p.50)

Como procedimento de pesquisa será realizado um estudo de caso que se justifica por visar o exame detalhado de uma situação em particular (Godoy, 1995a apud Bertucci, 2008).

Conforme Yin (2001), o estudo de caso é um método rigoroso de pesquisa, através de uma abordagem sistêmica e sociológica sobre os acontecimentos. Permite ao investigador um aprofundamento em relação ao fenômeno estudado, principalmente quando se trata de pesquisas em ciências humanas e que contribui para a compreensão que temos dos fenômenos individuais, organizacionais, sociais e políticos.

Yin (2001) entende que o estudo de caso, sendo uma investigação empírica, é o método ideal quando o pesquisador tem pouco controle sobre os eventos e quando o foco se encontra em fenômenos contemporâneos inseridos dentro de seu contexto da vida real, principalmente quando os limites entre o fenômeno e o contexto não estão claramente definidos. O Estudo de Caso revela nuances difíceis de serem enxergadas "a olho nu".

Yin (2001) considera que as várias fontes de coleta de dados são complementares, e que um bom estudo de caso utiliza o maior número possível de fontes. Dessa forma, as técnicas utilizadas para coletar dados nesse estudo serão a coleta documental e a entrevista.

Quanto à coleta documental, a pesquisa poderá valer-se de documentos como Nota Técnica que ensejou o programa e relatório de resultado do programa, dados primários; e regulamento, termos de adesão e rescisão, dados secundários. Essa categorização está de acordo com Bertucci (2008) que considera as fontes de dados primários aqueles documentos que ainda não se tornaram públicos e secundários aqueles que já foram disponibilizados ao público.

Pretende-se através desses documentos entender porque a Empresa institui Plano de Desligamento Voluntário e como isso pode implicar sua gestão do seu Capital Humano.

Yin (2001) destaca como vantagens da coleta documental sua estabilidade, ou seja, poder ser revisada inúmeras vezes; sua discrição, por não ser criada como resultado do estudo de caso; sua exatidão, por conter nomes, referências e detalhes exatos de um evento; e sua ampla cobertura, longo espaço de tempo, muitos eventos e muitos ambientes distintos. 
Para Bertucci (2008), a entrevista é realizada por pelo menos duas pessoas e consiste em uma indagação direta para conhecer a perspectiva do empregado sobre o assunto pesquisado, sendo de natureza subjetiva. Esse instrumento é um dos mais úteis para coleta de dados na área de ciência social, inclusive nas ciências gerenciais.

Yin (2001) apresenta a entrevista como uma das mais importantes fontes de informações para um estudo de caso, pois constituem uma fonte essencial de evidências, já que a maioria delas trata de questões humanas.

Segundo Yin (2001), as vantagens da técnica de entrevista é ser direcionada, enfocar diretamente o tópico do estudo de caso e ser perceptiva, - fornecer inferências causais percebidas.

\section{DESENVOLVIMENTO}

\subsection{COLETA DE DADOS}

Os instrumentos de coleta de dados utilizados foram: entrevista semiestruturada com os empregados da área de Recursos Humanos, envolvidos na implementação e operacionalização do PDV, e gestores de empregados que aderiram ao PDV, além das fontes documentais.

As entrevistas realizadas com os sujeitos da pesquisa tiveram, em média, duração de 30 minutos e durante sua realização foram anotadas palavras-chave, sendo os seus conteúdos imediatamente reconstruídos após as realizações, objetivando a análise de discurso.

Fizeram parte da análise as seguintes fontes documentais: 03 documentos relativos ao PDV (Nota Técnica de proposição, regulamento do plano e relatórios de apresentação de resultado), o Plano de Cargos, Carreiras e Salários da Empresa e o próprio banco de dados que permitiu o acesso ao tempo de empresa e o estágio da carreira de cada empregado que aderiu ao Plano.

As informações utilizadas no estudo referem-se aos dados e desligamentos dos empregados programados até a data limite de desligamento previsto no Regulamento do Plano.

Os entrevistados foram convidados por correio eletrônico enviado no dia 20/03/2015, sendo elucidados a cerca do objetivo, amplitude da pesquisa e confidencialidade das respostas. As entrevistas ocorreram entre os dias 25 e 26 do mês de março de 2015.

\subsection{ANÁLISE DE DADOS}

Conforme documentos analisados, o PDV da empresa aqui analisada objetivava diretamente adequar os recursos humanos presentes às suas reais necessidades, restabelecendo o equilíbrio na curva de maturidade profissional ao diminuir a média de idade de seus empregados, otimizando os custos por meio da modernização e, consequentemente, o desenvolvimento da dinâmica de seu Plano de Cargos, Carreiras e Salários. 
Trabalhando com dados gerais, é possível identificar a idade média do quadro de pessoal em 44 anos, sendo que aproximadamente $32 \%$ do total de empregados possuem tempo superior a 23 anos de trabalho na empresa.

Analisando o relatório de resultados do Plano tem-se o total de aderentes por cargo:

TABELA 1 - Quantidade de aderentes por cargo

\begin{tabular}{l|c|c} 
CARGo & QUANTIDADE & PERCENTUAL \\
\hline Operador Industrial & 52 & $35,78 \%$ \\
\hline Assistente Técnico Administrativo & 19 & $16,51 \%$ \\
\hline Analista & 14 & $11,01 \%$ \\
\hline Técnico Industrial & 9 & $6,42 \%$ \\
\hline Ag. Especial de Combate Incêndio & 3 & $2,75 \%$ \\
\hline Gerente III & 3 & $2,75 \%$ \\
\hline Ag. Especial de Segurança & 2 & $1,83 \%$ \\
\hline Cozinheiro & 2 & $1,83 \%$ \\
\hline Gerente & 2 & $1,83 \%$ \\
\hline Agente de Segurança & 1 & $0,92 \%$ \\
\hline Projetista de Valores & 1 & $0,92 \%$ \\
\hline Técnico de Suporte & 1 & $0,92 \%$
\end{tabular}

FONTE: Dados Empíricos da Pesquisa

Pode-se perceber que a maior quantidade de empregados que fizeram adesão ao PDV são da carreira de Operador Industrial, que segundo Plano de Cargos, Carreiras e Salários da empresa tem como missão contribuir para o efetivo funcionamento dos processos produtivos, mediante a execução de atividades de sua área de atuação, visando à otimização das operações da Empresa e à manutenção dos padrões de qualidade e segurança requeridos. Esse cargo está relacionado à atividade fim da Empresa e conforme sua missão pode-se inferir que está diretamente ligado à capacidade produtiva da Empresa.

Segundo informações da Nota Técnica que criou o Plano, por considerar que o PDV implica riscos em relação à possível perda de bons funcionários, a Empresa estimula a transmissão de conhecimentos por meio da promoção de grupos de trabalho compostos por diferentes gerações. Acredita, dessa forma, estar se preparando para que não tenha resultados negativos com a ausência dos empregados desligados.

Além disso, tal Nota Técnica determinou a criação de uma Comissão para avaliar os casos em que fosse necessária a permanência do empregado elegível e optante pela adesão ao PDV por tempo previamente determinado a pedido da empresa, visando principalmente à passagem programada de conhecimentos a outros empregados com potencial de assumirem papéis estratégicos.

Assim, a comissão analisou a lista dos aderentes e designou a data de desligamento para os grupos de colaboradores. Os períodos considerados foram: imediatamente, considerando o prazo para os trâ- 
mites necessários ao desligamento de cerca de 30 dias, 120 dias ou 240 dias após adesão ao plano.

Os desligamentos ocorrem conforme ordem cronológica que atenda ao programa de passagem de conhecimento e sua extensão e se dará da seguinte forma:

TABELA 2 - Quantidade de desligamento por mês

\begin{tabular}{l|c}
\multicolumn{1}{c|}{ MÊS } & QUANTIDADE \\
\hline Dez-14 & 24 \\
\hline Jan-15 & 18 \\
\hline Feb-15 & 10 \\
\hline Mar-15 & 7 \\
\hline Abr-15 & 10 \\
\hline Mai-15 & 4 \\
\hline Jun-15 & 3 \\
\hline Jul-15 & 33 \\
\hline Total: & 109
\end{tabular}

FOnTE: Dados Empíricos da Pesquisa

GRÁfICO 1 - Percentual por mês de desligamento

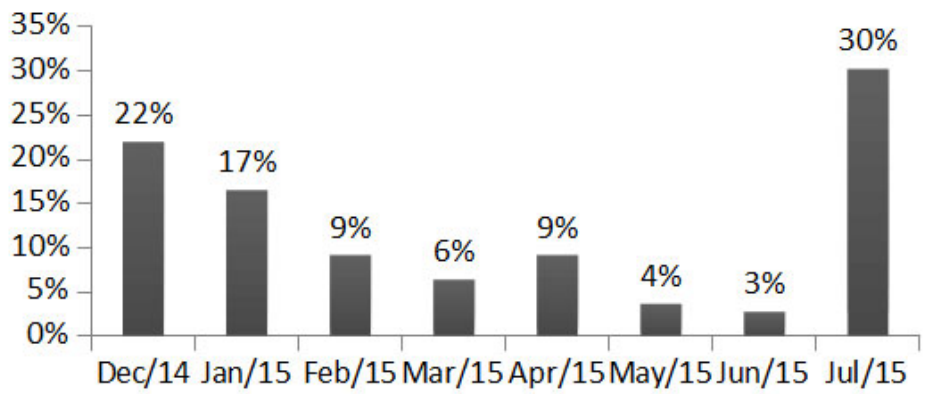

Entendendo que os desligamentos programados para a data limite previamente estabelecida (julho de 2015) são aqueles cujos empregados que terão que cumprir um programa de transferência de conhecimento mais longo, provavelmente pela importância de suas atividades e conhecimentos acumulados, as análises que seguem debruçam-se sobre os desligamentos previstos para esse mês. Assim, temos os seguintes aspectos:

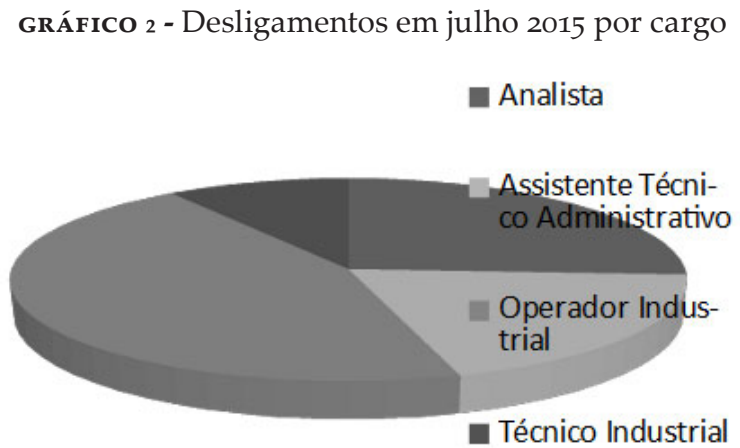


Dos 30\% que tiveram sua data programada para julho de 2015 $43 \%$ são Operador Industrial (14 empregados). Ao se falar deste cargo, deve-se observar as especificidades das máquinas e processos produtivos em que estão envolvidos, tendo nesta Empresa atividades mais específicas e particulares quando comparado ao operador industrial de mercado. $\mathrm{O}$ operador industrial é o responsável pela produção de todo e qualquer produto oferecido pela empresa estudada e detêm o conhecimento de seus processos produtivos e medidas de segurança.

Desses 14 empregados, que para atender as necessidades da empresa de compartilhamento programado de informações só poderão se desligar em julho de $2015,93 \%$ tem mais de 29 anos de empresa e $72 \%$ atuam como mestre, nível de carreira que além da capacidade de mestrança exige dos empregados competências tais como liderança, resolução de problemas, geração e disseminação do conhecimento.

Com relação à análise dos discursos obtidos por meio das entrevistas realizadas pode-se perceber que quando perguntados com relação aos aspectos positivos do PDV, os empregados conseguem ressaltar questões ligadas ao Capital Humano: "Acontecerá uma renovação no quadro de pessoal de forma "natural" proporcionando o processo sucessivo com a disseminação do conhecimento"; "O PDV (...) no nosso caso, foi importante, pois conseguimos liberar vagas para serem preenchidas por profissionais com boa formação e mais energia."

Quando perguntados especificamente sobre a contribuição do PDV para a Gestão do Capital Humano, os entrevistados, de acordo com o discurso, percebem que: "por ser uma forma de desligamento planejado, força os gestores a identificarem talentos dentro da própria organização para absorverem as atribuições daqueles que serão desligados. Neste ponto, surgem novas lideranças, profissionais se desenvolvem com maior velocidade e, em geral, a Empresa se beneficia" e ainda que o PDV possa contribuir quando "conte com a previsão de transmissão de conhecimento dos empregados a serem desligados."

Com relação ao programa de passagem programada de conhecimento os empregados percebem que é importante "principalmente se os processos da empresa não estiverem mapeados e normatizados" e que "é importante que a disseminação de conhecimentos seja repassada gradativamente, evitando possíveis perdas e prejuízos à realização dos processos".

Dentre os discursos analisados ainda destaca-se a realidade envolvida: "foi possível indicar um engenheiro para acompanhar todas as atividades do empregado que aderiu ao plano. Desta forma, tivemos tempo suficiente para não prejudicar as atividades desempenhadas por ele. É evidente que, caso não houvesse o PDV, em algum momento, este desligamento ocorreria de forma abrupta, o que certamente traria consideráveis prejuízos ao desempenho deste Departamento".

Com relação à passagem do conhecimento ainda destaca-se: "em alguns meses, foi possível uma transferência de boa parte de suas atribuições, sem grandes prejuízos. É evidente que perdemos parte do co- 
nhecimento histórico de alguns projetos, mas isto não trouxe grandes problemas, uma vez que os registros mais relevantes foram passados ao novo engenheiro".

Pode-se perceber a importância do PDV e sua contribuição para a Gestão do Capital Humano no seguinte discurso de um gestor: "Acredito que, como a demissão é programada e, consequentemente, planejada, é possível evitar que perdas repentinas de empregados levem embora conhecimentos vitais para a produtividade. Com o plano, as gerências imediatas podem se programar para a perda daquele empregado, o que, por si só, já evita quedas na produtividade" e ainda "caso não houvesse este programa, certamente o profissional levaria consigo todo o conhecimento e experiência adquiridos ao longo de muitos anos na Empresa. O programa de gestão de conhecimento é fundamental para a continuidade dos processos de forma eficiente".

\section{CONCLUSÃO}

Este artigo buscou explorar como a adoção de um Plano de Desligamento Voluntário em uma Empresa Pública pode funcionar como instrumento para a Gestão do Capital Humano. Para endereçar a problemática proposta, optou-se por um estudo de caráter qualitativo a partir da análise de conteúdo de documentos institucionais e entrevistas de campo.

De forma substantiva, por meio da análise dos discursos expressos nas entrevistas, observou-se que o PDV pode contribuir para a Gestão do Capital Humano da seguinte forma: (i) possibilitou o planejamento para desligamento; corroborando os argumentos de Leme (2000), Leme e Mazzoli (2001) e Barbosa et al (2011), e; (ii) permitiu a implementação de um programa de passagem de conhecimento, impossibilitando que o conhecimento se perdesse como ocorre com desligamentos repentinas e não planejadas; observações estas que vão ao encontro das ideias advogadas por Silva et al (2009) e Monteiro (2012).

Ademais, por meio da análise de documentos da empresa percebeu-se que o PDV objetivou a programação do desligamento; conforme exposto por Bessi e Grisci (2003) e o planejamento de transmissão de conhecimento de alguns empregados cujas atividades, devido as suas importâncias, possuem impacto considerável na produtividade da empresa, evitando possíveis transtornos de rotatividade expostos por Nomura e Goidzinski (2005) e Spector (2010).

Não obstante, a análise dos dados permitiu inferir que a empresa se preparou para a saída de empregados em posições estratégicas, conforme alerta de Assis (2010). De outro lado, pelas entrevistas, depreende-se que o PDV foi importante para a preparação para a saída de empregados que estavam, inevitavelmente, perto de se desligarem e que o Programa de passagem de conhecimento é essencial para que a empresa mantenha domínio dos seus processos de trabalho conforme argumentado por Caldas (2000) e Assis (2010). 
Apesar da literatura considera o PDV como um momento de perda de mão-de-obra qualificada, esse estudo buscou apresentar, pelo contrário, que esse é um momento de levantar possibilidades como planejamento e preparação (Ghiorzi, 2004), pois a perda de alguns profissionais que se desligariam da empresa mais cedo ou mais tarde de forma abrupta, é inevitável; transferência de conhecimento (Monteiro, 2012) e diagnóstico de novos talentos.

Salienta-se que a pesquisa não conseguiu medir o impacto dos desligamentos na produtividade da empresa, nem tampouco se a transmissão de conhecimentos foi efetiva e positiva com relação à capacidade produtiva de determinados setores da empresa.

Futuras pesquisas devem buscar analisar a produtividade de setores impactados pelas saídas de empregados, especialmente se for possível comparar a capacidade produtiva antes e depois da implantação de um PDV, além de buscarem a efetividade de programas de transferência de conhecimentos ligados ao PDV.

\section{REFERENCIAL BIBLIOGRÁFICO}

Assis, M., T.(2010). Indicadores de gestão de recursos

humanos. Rio de Janeiro: Qualitymark.

Barbosa, T. M.; vieira, N. S; campos, D. C.S. (2011) Consequências dos Programas de Demissão Voluntário - PDV: um estudo de caso na CEMIG.

VIII Simpósio de Excelência em Gestão e Tecnologia, SEGeT, Resende, RJ.

Bertucci, J.L.O. (2008) Metodologia básica para elaboração de trabalhos de conclusão de cursos (TCC): ênfase na elaboração de TCC de pós-graduação Lato Sensu. São Paulo: Atlas.

Bessi, V.G; Grisci, C.L.I. (2003) Daqui pra frente vai ter que ser diferente: programa de apoio à demissão voluntária em tempos de reestruturação produtiva do trabalho bancário. Encontro Nacional dos Programas de Pós-Graduação em Administração ENANPAD, Atibaia, SP. Anais... Atibaia: ANPAD.

Caldas, M. P. (2000). Demissão: causas, efeitos e alternativas para empresa e indivíduo. São Paulo: Atlas.

DUTRA, J. S. (2002) Gestão de pessoas: modelo, processos, tendências e perspectivas. São Paulo: Atlas.

Gerhardt, T.E.; Silveira, D.T. (2009) Métodos de Pesquisa. Porto Alegre: Editora da UFRGS.

Ghiorzi, S. B. (2004) Consequências da adesão ao plano de demissão incentivada em uma instituição bancária na ótica dos empregados.

UDESC. Dissertação de Mestrado. Florianópolis.

Guedes, V., A.; Calado, S., M. R.; Vieira, M., M. F. (1998) Programa de desligamento voluntário um estudo sobre os fatores determinantes da adesão entre ex-funcionários de instituição financeira governamental. Anais do $22^{\underline{0}}$ Encontro Anual do ANPAD, Área Temática Recursos Humanos. Foz do Iguaçu, Paraná. 
Leme, P. R. S. P. (2000) Análise do significado do programa de demissões voluntárias do Banco do Brasil. UFRGS. Dissertação de Mestrado. Rio Grande do Sul.

Leme, P.R.S.P.; Mazzilli, C. (2001) Análise do programa de demissões voluntárias do Banco do Brasil. Encontro da Associação Nacional de PósGraduação e Pesquisa em Administração - ENANPAD. Anais ... Campinas - SP.

Monteiro, L. E. S. (2012) Importância do Plano de Carreira e remuneração para a redução do turnover dentro das empresas - caso Eletrobrás FGV. Dissertação de Mestrado apresentada a EBAPE Rio de Janeiro.

Nomura, F. H.; Gaidzinski, R. R. (2005) Rotatividade da equipe de enfermagem: estudo em hospital-escola. Revista Latino-Americana de Enfermagem, v. 13, n. 5, p. 648-653.

Oliveira, J. A., Medeiros, M. P.M. (2011) Gestão de Pessoas no Setor Público. Florianópolis: Departamento de Ciências da Administração / UFSC; [Brasília] : CAPES : UAB.

Silva, R. S. da.; et al. (2009) Abordagem Probabilística do Impacto do Programa de Demissão Voluntária sobre a Gestão do Capital Humano. Encontro da Associação Nacional de Pós-Graduação e Pesquisa em Administração - ENANPAD. Anais. São Paulo.

Spector, P. E. (2010). Psicologia nas organizações. São Paulo: Saraiva.

Yin, R. K.(2001). Estudo de Caso: Planejamento e Métodos. Porto Alegre : Bookman. 